Research Paper

\title{
Magnitude of Gene Mutations Conferring Drug Resistance in Mycobacterium Tuberculosis Isolates from Lymph Node Aspirates in Ethiopia
}

\author{
Fantahun Biadglegne ${ }^{1,2,3,5 凶}$, Belay Tessema ${ }^{4}$, Arne C. Rodloff ${ }^{2}$, Ulrich Sack ${ }^{3,5}$ \\ 1. College of Medicine and Health Sciences, Bahir Dar University, Bahir Dar, Ethiopia; \\ 2. Institute of Medical Microbiology and Epidemiology of Infectious Diseases, University Hospital, University of Leipzig, Leipzig, Germany; \\ 3. Institute of Clinical Immunology, University Hospital, University of Leipzig, Leipzig, Germany; \\ 4. College of Medicine and Health Sciences, University of Gondar, Gondar, Ethiopia; \\ 5. Translational Centre for Regenerative Medicine (TRM)-Leipzig, University Hospital, University of Leipzig, Leipzig, Germany.
}

$\square$ Corresponding author: Fantahun Biadglegne Degeneh, Institute of Medical Microbiology and Epidemiology of Infectious Diseases, Medical Faculty, University of Leipzig, Liebigst 21, D-04103 Leipzig, Germany. Fax: +49 341 9715209, Tel: +49 15734812055 e-mail: fantahun.degeneh@gmail.com.

(c) Ivyspring International Publisher. This is an open-access article distributed under the terms of the Creative Commons License (http://creativecommons.org/ licenses/by-nc-nd/3.0/). Reproduction is permitted for personal, noncommercial use, provided that the article is in whole, unmodified, and properly cited.

Received: 2013.05.31; Accepted: 2013.08.12; Published: 2013.09.12

\begin{abstract}
Objective: Resistance to drugs is due to particular genomic mutations in the specific genes of Mycobacterium tuberculosis. Timely genetic characterization will allow identification of resistance mutations that will optimize an effective antibiotic treatment regimen. We determine the magnitude of gene mutations conferring resistance to isoniazid (INH), rifampicin (RMP) and ethambutol (EMB) among tuberculosis (TB) lymphadenitis patients.

Methods: A cross sectional prospective study was conducted among 226 M.tuberculosis isolates from culture positive lymph node aspirates collected from TB lymphadenitis patients between April 2012 and May 2012. Detection of mutations conferring resistance to drugs was carried out using GenoType ${ }^{\circledR}$ MTBDRplus and GenoType $₫$ MTBDRsl assay.

Results: Out of the 226 strains, mutations conferring resistance to INH, RMP, multidrug resistance tuberculosis (MDR-TB) and EMB were 8, 3, 2 and 2 isolates, respectively. There was no isolated strain that showed mutation in the inhA promoter region gene. All INH resistant strains had mutations in the kat $G$ gene at codon 315 with amino acid change of S3I5TI. Among rifampicin resistant strains, two isolates displayed mutations at codon $53 \mathrm{I}$ in the rpoB gene with amino acid change of S53IL and one isolate was by omission of wild type probes at Q5I3L. According to mutations associated with ethambutol resistance, all of the isolates had mutations in the embB gene with aminoacid change of M306l. All isolates resistant to INH, RMP and MDR using BacT/AlerT 3D system were correctly identified by GenoType $\AA$ MTBDRplus assay.

Conclusion: We observed mutations conferring resistance to INH at $\mathrm{S} 3 \mathrm{I} 5 \mathrm{TI}$ of the kat $G$ gene, RMP at S53IL and Q5 I $3 \mathrm{~L}$ in the $r p o B$ genes and EMB at M306I of the embB gene. In the absence of conventional drug susceptibility testing, the effort to develop easy, rapid and cost effective molecular assays for drug resistance TB monitoring is definitely desirable and the GenoType $®$ MTBDRplus assay was found to be a useful method for diagnosis of resistance to INH, RMP and MDR from lymph node aspirates. Further molecular cluster analysis to determine transmission dynamics of mutated strain is required.
\end{abstract}

Key words: Isoniazid, Rifampicin, Ethambutol, Mutation, M.tuberculosis, aspirates, Ethiopia.

\section{Introduction}

Developing countries, particularly Ethiopia, have experienced a major increase in the burden of
$\mathrm{TB}$, one of the most serious public health challenges. Ethiopia ranks third in terms of the number of ex- 
traplumonary tuberculosis (EPTB) cases worldwide (1). EPTB affects different organs of human body where TB lymphadenitis is the most common manifestations of all EPTB (2). The most commonly involved lymph nodes were cervical, axilla, inguinal and abdominal sites. Cervical lymph nodes are the most commonly affected group of nodes reported (3).

M. tuberculosis drug resistance is a global concern. In Ethiopia, the estimated incidence rate of all forms of TB was 220/100,000 population (4) and 63 $/ 100,000$ population for smear positive cases (5). In 2012, WHO Global TB report showed Ethiopia ranks as $15^{\text {th }}$ among 27 high TB burden multi drug-resistant TB (MDR-TB) countries (4). MDR-TB defined as resistance to at least isoniazid and rifampicin was 1.6\% for new cases and $12 \%$ for previously treated TB cases, respectively (4). MDR-TB is more difficult and costly than normal TB to treat, and is more often fatal. Culture based drug susceptibility testing (DST) method can provide definitive results, but are labour intensive and time consuming, usually requires at least 14 days for primary isolation of the organism and another 14 days for drug susceptibility test (6). Molecular methods that target drug resistance mutations are a suitable approach for a rapid drug susceptibility testing (7).

GenoType MTBDRplus and GenoType MTBDRsl assay (Hain Life Science $\mathrm{GmbH}$, Nehren, Germany); have been described for mutation detection. To observe drug resistance molecularly, the magnitude of drug resistance conferring mutations in a certain setting needs to be identified, and such information is presently missing for TB lymphadenitis patients in Ethiopia. With this background, this study attempts to assess the magnitude of gene mutations associated with drug resistance among M.tuberculosis isolates from lymph node aspirates.

\section{Materials and Methods}

\section{Study design and subjects}

This prospective cross-sectional study was conducted at four main hospitals (Felege Hiwot, Gamby, Gondar, and Dessie) and at the Bikat Diagnostic Clinic located in northern Ethiopia. Specimens were collected between April and May of 2012. Clinical and cytological suspected 437 TB lymphadenitis cases and signed the written consent were included in our study. A structured and pretested questionnaire was used to collect demographic characteristics of study subjects. Ethical clearance was obtained from research and publication committee ethical review board of the Bahir Dar University, Bahir Dar, Ethiopia.

\section{Specimen collection, storage and transport}

The fine needle aspirated samples were collected from lymph nodes of all patients. Fine needle aspirates (FNAs) were divided into two halves one for cytology and the other for culture. The cytological criteria for diagnosis of TB lymphadenitis have been made based on the presence of epitheloid cell granuloma with or without multinucleated giant cells and with or without caseous necrosis or degenerate caseous necrosis and/liquefied necrotic material with marked degenerating and viable inflammatory cell infiltration without epitheloid granuloma (8). The culture FNAs was washed into $1 \mathrm{ml}$ of phosphate buffer saline $(\mathrm{pH}=6.8)$ and stored at $-80^{\circ} \mathrm{C}$ until transported to the laboratory in Leipzig, Germany for mycobacteriological analysis.

Specimens were packed on ice and transported according to regulation provided by the International Air Transport Association (http://www.iata.org/ ads/issa/htm).

\section{Culture and species identification}

FNAs were processed for culture according to Deutsches Institut fur Normung (DIN) recommendations for the detection of mycobacteria by culture methods (9). For species identification and differentiation of $M$. tuberculosis complex strains from cultures, the GeneType MTBC assay was performed according to the instructions of the manufacturer (Hain Life Science $\mathrm{GmbH}$, Nehren, Germany) at the mycobacteriology laboratory in the Institute of Medical Microbiology and Epidemiology of Infectious Diseases.

\section{Molecular testing}

GenoType ${ }^{\circledR}$ MTBDRplus assay for detection of INH and RMP resistance, and GenoType ${ }^{\circledR}$ MTBDRsl assay for detection of EMB resistance were performed according to the manufacturer's recommendations (Hain Life Science GmbH, Nehren, Germany). Using multiplex PCR the genes responsible for drug resistance such as katG, inh $A, r p o B$ and $e m b B$ were amplified and the resulting biotin-labeled amplicons were hybridized to DNA probes bound to membrane probes. Briefly, for amplification $35 \mu \mathrm{l}$ of a primer nucleotide mixture, amplification buffer containing $5 \mu \mathrm{l}$ $\mathrm{mM} \mathrm{MgCl} 2,2.5 \mu l$ sterile water, $2.5 \mu \mathrm{l}$ (1 unit) Taq DNA polymerase (ROCHE, Mannheim, Germany), and $5 \mu \mathrm{l}$ of DNA in a final volume of $50 \mu \mathrm{l}$ were used. The amplification protocol consisted of $15 \mathrm{~min}$ at $95^{\circ} \mathrm{C}$ for denaturation, followed by 10 cycles comprising $30 \mathrm{~s}$ at $95^{\circ} \mathrm{C}$ and $2 \mathrm{~min}$ at $58^{\circ} \mathrm{C}$, an additional 20 cycles comprising $25 \mathrm{~s}$ at $95^{\circ} \mathrm{C}, 40 \mathrm{~s}$ at $53^{\circ} \mathrm{C}$, and $40 \mathrm{~s}$ at $70^{\circ} \mathrm{C}$, and a final extension at $70^{\circ} \mathrm{C}$ for $8 \mathrm{~min}$. Hybridization of the single stranded, biotin-labeled amplicons to membrane-bound probes on the strip followed by addition of conjugate, and substrate to detect visible band patterns on the strip was performed manually using a 
shaking water bath, Memmert-SV1422 (Memmert $\mathrm{GmbH} \& \mathrm{CO}$. KG, Schwabach, Germany) at $45^{\circ} \mathrm{C}$. Then strips were allowed to dry and interpreted according to the instructions provided by the manufacturer.

For each gene, GenoType ${ }^{\circledR}$ MTBDRplus and GenoType ${ }^{\circledR}$ MTBDRsl assay tests for presence of wild type (WT) and mutant (MUT) probes. The membrane bound DNA probes included eight $r p o B$ wild-type probes, four $r p o B$ mutant probes in positions with D516V, H526Y, H526D, and S531L, one katG wild-type probe, two katG mutant probes with S315T1 and S315T2, two inhA wild-type probes and four inhA mutant probes with C15T, A16G, T8C, and T8A. For detection of EMB resistance, the GenoType ${ }^{\circledR M T B D R s l}$ employs one wild-type probe (WT-306) and two mutation probes specific for mutations M306I and M 306V in the embB gene. Following the manufacturer's instructions (Hain Life science $\mathrm{GmbH}$, Nehren, Germany), susceptibility to anti-TB drugs was defined as hybridization to all the wild type probes and no hybridization to the mutant probes.

\section{Phenotypic testing}

As previously described (10), phenotypic method of drug susceptibility testing (DST) for INH, RMP and EMB was performed by BacT/AerT 3D system (BioMerieux, S.A, France).The test concentration for INH and RMP was $1 \mu \mathrm{g} / \mathrm{ml}$ and $2 \mu \mathrm{g} / \mathrm{ml}$ for EMB. Two controls, one with $1 \%$ control $(0.5 \mathrm{ml}$ of the $1: 100$ diluted test organisms suspension) and one original control without drug were used for interpretation of the test results. $M$. tuberculosis isolate was determined to be resistant to an antibiotic when the drug containing bottle had a time to detection (TTD) that was less than or equal to the TTD of the $1 \%$ control.

\section{Data management and analysis}

All data were entered, cleared, and analyzed using the SPSS statistical software package, Version 16 (SPSS Inc., Chicago, IL, USA). Resistance results of BacT/Alert 3D system and GenoTypeMTBDR plus assay were compared. Descriptive data analysis was used to visualize differences within data and chi-squared test was applied to assess factors associated with drug resistance $\mathrm{TB}$ in terms of the odds ratio and its $95 \%$ confidence interval (CI). Differences were considered significant when $p$-value less than or equal to 0.05 .

\section{Results}

A total of 226 isolates from culture positive lymph node aspirates were included in this study. One hundred thirty $(57.5 \%)$ of the 226 , isolates were from female and $26(11.5 \%)$ were from paediatric patients $(\leq 14$ years old). The molecular method DST results showed that $13(5.8 \%)$ of the isolates had mutations conferring resistance to INH, RMP and EMB (Table 1). Previous treatment history for TB and sex was significantly associated with the occurrence of gene mutations to any anti-TB drugs (INH, RMP and EMB $(\mathrm{P}=0.010)$. A chi squared test analysis of factors associated to any one of the three anti-TB drugs is summarized in Table 2. In this study, out of the total molecular method DST, mutations were detected in $13(5.8 \%)$ isolates. Of these, $8(3.5 \%)$ contained a katG gene mutation, $3(1.3 \%)$ was in $r p o B$ gene and, $2(1 \%)$ were in $e m b B$ gene. In this study, 2 isolates $(1 \%)$ showed mutation in both $r p o B$ and $k a t G$ gene. There was no isolates that shows mutation in inhA promoter region gene. Drug resistant strain associated to INH at $4(2.3 \%)$, RMP at $1(0.6 \%)$ and MDR-TB at $1(0.6 \%)$ were detected from cervical lymph nodes. Two isolates of the MDR-TB strain was diagnosed from patients with discrete lymph nodes (Table 3).

In this study, out of mutation in katG gene conferring INH resistant strain, all INH resistant isolates had mutations in the katG gene at codon S315T1, indicating high level of INH resistance. All of the katG mutations detected at wild type are also observed at mutant probes. Of the rifampicin resistant 2 isolates displayed mutations at S531L in the rpoB gene. Furthermore 1 isolate was indicated by omission of wild type probe (WT3) at codon Q513L with no developing mutations band. Among ethambutol resistance strains, all of the isolates had mutations in the $e m b B$ (codon 306) gene with amino acid change of M306I (Table 4).

The comparison between the automated, conventional based BacT/AlerT 3D system DST and GenoType ${ }^{\circledR}$ MTBDRplus assay towards INH and RMP drugs is shown in Table 5. The two methods had a $100 \%$ agreement. All isolates resistant to INH, RMP and MDR tested using BacT/AlerT 3D system were correctly identified by GenoType ${ }^{\circledR}$ MTBDRplus assay.

\section{Discussion}

M. tuberculosis is the leading cause of infectious disease related mortality in Ethiopia today. Resistance to drugs is due to particular genomic mutations in the specific genes of M.tuberculosis. Timely genetic characterization will allow identification of resistance mutations that will optimize an effective antibiotic treatment regimen. Thus, we conducted this study, to determine the magnitude of gene mutations conferring resistance to INH, RMP and EMB among TB lymphadenitis patients in Ethiopia. 
Table I. Distribution of anti TB drug resistance with different variables.

\begin{tabular}{|c|c|c|c|c|c|}
\hline \multirow[t]{3}{*}{ Variables } & \multicolumn{4}{|c|}{ Anti-TB drug resistance } & \multirow{3}{*}{$\begin{array}{l}\text { EMB } \\
\text { N (\%) }\end{array}$} \\
\hline & No. of patients & INH & RMP & MDR & \\
\hline & & $\mathrm{N}(\%)$ & $\mathrm{N}(\%)$ & $\mathrm{N}(\%)$ & \\
\hline \multicolumn{6}{|l|}{ Sex } \\
\hline Male & 96 & $5(62.5)$ & $2(66.7)$ & $2(100)$ & $2(100)$ \\
\hline Female & 130 & $3(37.5)$ & $1(33.3)$ & $0(0)$ & $0(0)$ \\
\hline \multicolumn{6}{|l|}{ Age group } \\
\hline Children & 26 & $0(0)$ & $1(33.3)$ & $0(0)$ & $0(0)$ \\
\hline Adults & 200 & $8(100)$ & $2(66.7)$ & $2(100)$ & $2(100)$ \\
\hline \multicolumn{6}{|c|}{ Treatment history of TB } \\
\hline New & 213 & $5(62.5)$ & $3(100)$ & $2(100)$ & $2(100)$ \\
\hline Retreated & 13 & $3(37.5)$ & $0(0)$ & $0(0)$ & $0(0)$ \\
\hline \multicolumn{6}{|c|}{ Contact history with TB patients } \\
\hline Yes & 109 & $5(62.5)$ & $0(0)$ & $0(0)$ & $0(0)$ \\
\hline No & 117 & $3(37.5)$ & $3(100)$ & $2(100)$ & $2(100)$ \\
\hline
\end{tabular}

Table 2. Chi squared test analysis of factors associated to any one of the three first line anti-TB drugs.

\begin{tabular}{|c|c|c|c|c|}
\hline Variables & No. of patients & $\begin{array}{l}\text { Resistant } \\
\mathrm{N}(\%)\end{array}$ & $\mathrm{OR}(95 \% \mathrm{CI})$ & $P$ value \\
\hline \multicolumn{5}{|l|}{ Sex } \\
\hline Male & 96 & $10(76.9)$ & $4.704(1.259-17.576)$ & 0.018 \\
\hline Female & 130 & $3(23.1)$ & 1.0 & \\
\hline \multicolumn{5}{|l|}{ Age group } \\
\hline Children & 26 & $1(7.7)$ & $0.64(0.0798-5.134)$ & 0.998 \\
\hline Adults & 200 & $12(92.3)$ & 1.0 & \\
\hline \multicolumn{5}{|c|}{ Treatment history for TB } \\
\hline New & 213 & $10(76.9)$ & $0.161(0.038-0.678)$ & 0.029 \\
\hline Retreated & 13 & $3(23.1)$ & 1.0 & \\
\hline \multicolumn{5}{|c|}{ Contact history with TB patients } \\
\hline Yes & 109 & $9(69.2)$ & $2.4903(0.744-8.331)$ & 0.158 \\
\hline No & 117 & $4(30.8)$ & 1.0 & \\
\hline
\end{tabular}

CI,confidence, OR,odds ratio

Table 3. Prevalence of gene mutations by lymph node region and clinical feature.

\begin{tabular}{|c|c|c|c|c|c|}
\hline \multirow[t]{2}{*}{ Infected sites } & \multicolumn{4}{|c|}{ Anti-TB drug resistance } & \multirow[b]{2}{*}{$\mathrm{MDR}^{\mathrm{d}}$} \\
\hline & Total & Sensitive $^{a}$ & $\mathrm{INH}^{\mathrm{b}}$ & RMPc & \\
\hline & $\mathrm{N}=226$ & $\mathrm{~N}=217$ & $\mathrm{~N}=6$ & $\mathrm{~N}=1$ & $\mathrm{~N}=2$ \\
\hline Cervical & 171 & $165(96.5)$ & $4(2.3)$ & $1(0.6)$ & $1(0.6)$ \\
\hline Axilla & 33 & $30(90.9)$ & $2(6.0)$ & $0(0)$ & $1(3.0)$ \\
\hline Inguinal & 15 & $15(100.0)$ & $0(0)$ & $0(0)$ & $0(0)$ \\
\hline other & 7 & $7(100.0)$ & $0(0)$ & $0(0)$ & $0(0)$ \\
\hline \multicolumn{6}{|l|}{ Clinical feature } \\
\hline Matted & 173 & 168(98.2) & $4(2.3)$ & $0(0)$ & $0(0)$ \\
\hline Discrete & 50 & $47(94.0)$ & $1(2.0)$ & $0(0)$ & $2(4.0)$ \\
\hline Other & 3 & $2(66.7)$ & $1(33.3)$ & $0(0)$ & $0(0)$ \\
\hline
\end{tabular}

a sensitive to both INH, RMP and EMB , b resistant to only INH, c resistant to only RMP, d resistant to both INH, RMP and EMB

Table 4. Mutations identified for isoniazid, rifampicin and ethambutol resistant M.tuberculosis isolates.

\begin{tabular}{lllll}
\hline Anti-TB drugs & No. of resistant isolates & $\begin{array}{l}\text { Pattern of gene mutations } \\
\text { (wild type/mutant) }\end{array}$ & Amino acid change & Result \\
\hline Isoniazid & 8 & $\Delta$ katG WT/ katG MUT1 & S315T & INH \\
Rifampicin & 1 & $\Delta$ rpoB WT3/ND & unknown & RMPr \\
& 2 & $\Delta r p o B$ WT8/ rpoB MUT3 & S531L & RMPr \\
Ethambutol & 2 & $\Delta$ embBWT1/embBMUT1A & M306I & EMB $^{r}$ \\
\hline r, resistant, $\Delta$, deletion. MUT, mutant, ND, no mutation detected at mutant probe. & &
\end{tabular}


Table 5. Comparison between GenoTypeMTBDRplus assay vs. BAcT/AlerT 3D system for detection of resistance to INH, RMP and MDR.

\begin{tabular}{|c|c|c|c|}
\hline \multirow[t]{2}{*}{ MTBDRplus assay } & & \multicolumn{2}{|c|}{ BacT/AlerT 3D system } \\
\hline & & Sensitive & Resistant \\
\hline \multirow[t]{2}{*}{ Isoniazid } & Sensitive & 218 & 0 \\
\hline & Resistant & 0 & 8 \\
\hline \multirow[t]{2}{*}{ Rifampicin } & Sensitive & 223 & 0 \\
\hline & Resistant & 1 & 2 \\
\hline \multirow[t]{2}{*}{ MDR-TB } & Sensitive & 224 & 0 \\
\hline & Resistant & 0 & 2 \\
\hline
\end{tabular}

DST, drug susceptibility test, MDR-TB, multidrug resistance tuberculosis.

The results of the GenoTypeMDRplus assay in this study were completely consistent with the results of phenotypic drug susceptibility testing, BacT/AlerT 3D system. There was a $100 \%$ agreement in drug susceptibility testing by the two methods for INH, RMP and combined resistance of INH and RMP (MDR). Similar results were reported by several studies ranging from $88.9-100 \%$ (11-14) for INH, RMP and MDR tested. The present study indicated that the high sensitivity to detect mutation resistance to INH, RMP and MDR from TB lymphadenitis patients indicates DNA probes used in GenoTypeMDRplus assay is potentially useful for rapid detection of gene mutations conferring drug resistant in M.tuberculosis isolates from lymph node aspirates in Ethiopia.

In our findings, out of the total gene mutations, four isolates resistant to INH, one isolate resistant to RMP and one isolate resistant to both INH and RMP (MDR-TB) were identified from the cervical lymph nodes of TB lymphadenitis cases. Most of them were from matted lymph nodes. This pattern clearly suggests that the late arrival of patients in seeking medical care. Persons with prolonged or intense contact with these cases are at high risk of becoming infected with drug resistant M.tuberculosis strain. In our findings, two MDR-TB strains were isolated from cases with discrete mobile lymph nodes, indicating that the occurrence of early infection with this disease (15). Molecular assay for drug resistance monitoring and public health education focusing on raising awareness of the disease due to infection with MDR-TB, sources of infection, mode of transmission and preventive methods is very important.

The majority of mutations conferring resistance to RMP $(73-100 \%)$ are typically found in a small region of amino acids located between position numbers $507-533$ of the rpoB gene $(11,16)$. The reported epidemiological data indicates the RMP resistant strains are widely spread in many areas of the world. In this study, two of three isolates with RMP re- sistance contained the S531L mutation; the most frequently reported resistance mutation in the Ethiopian strains $(11,17-24)$. However, in one isolate, we determined the absence of wild type probes (WT3) band indicating resistance to RMP; nevertheless, we cannot determine definitively the exact amino acid residue that confers this resistance.

$K a t G$ gene is the most commonly targeted region with majority of mutations occurred in codon 315 in $30-90 \%$ of INH resistant strains depending on geographical distribution (25). Most reports suggest that resistance of M.tuberculosis to INH showing mutation at codon $315(26,27)$. Findings of our study were similar with $100 \%$ of all isolates showing mutations at S315T1, attributed to high level of drug resistance to INH. Similar mutation trends to our finding at S315T1 of the katG gene, were reported in other study from northwest Ethiopia 100\% (11), indicating the possible transmission of strains with similar type of mutations in the community. However, in our study gene mutation attributed to low level drug resistance mainly caused by the mutations in the promoter region of inhA gene could not be observed. Similar findings were reported from the studies conducted in Spain (15) and Myanmar (28). In contrast to this study, high and low level of frequency of inhA mutation was reported from Tunisia 36.1\% (29), Canada 26\% (30) .

In this study, all of gene mutation among strains that are resistant to EMB by GenoType ${ }^{\circledR}$ MTBDRsl assay was observed at codon M306I in the embB gene. Mutation M306I has been also reported in Ethiopia from pulmonary tuberculosis patients (11). In our study, mutations detected among all isolates of M.tuberculosis showed resistant to EMB were also resistant to both INH and RMP, indicating that they were MDR strains of M.tuberculosis. In this study, GenoTypeMDRplus assay detects these resistances that have their origins in the rpoB, katG and inhA regions examined here. According to the manufacturers' instructions for use a major limitation of the test remains that not all mutations conferring resistance to RMP and INH anti-TB drugs are known. In this study, however, a good concordance was observed between BacT/AlerT 3D system drug susceptibility testing and GenoType MTBDR plus assay.

In conculusion, the results obtained indicate that, gene mutations conferring resistance to INH observed at S315T1 of the katG gene, RMP at S531L and Q513L in the $r p o B$ genes and EMB at M306I of the $e m b B$ gene. A close monitoring of gene mutations conferring to drug resistance in TB lymphadenitis patients is important. Although GenoTypeMDRplus assay is not a novel molecular assay, our results demonstrated that it is a rapid and potentially reliable assay for detection of gene mutations associated with drug resistance in 
TB lymphadenitis patients. In the absence of conventional drug susceptibility testing, the effort to develop easy, rapid and cost effective molecular assays for drug resistance TB monitoring would be of great importance. GenoType ${ }^{\circledR}$ MTBDRplus assay was found to be a useful method for diagnosis of resistance to INH, RMP and MDR from lymph node aspirates. Further molecular cluster analysis to determine transmission dynamics of mutated strain is required.

\section{Acknowledgments}

This study was carried out with financial support from the German Federal Ministry of Education and Research (BMBF, PtJ-Bio, 0315883), Translational Centre for Regenerative Medicine (TRM)-Leipzig, University Hospital Leipzig, Germany, the Institute of Medical Microbiology and Epidemiology of Infectious Disease, University Hospital Leipzig, Germany the German Academic Exchange Service (DAAD) and University of Bahir Dar, Ethiopia.

We express our deep appreciation to Dr Jörg Beer and Elisabeta Krawczyk for their kindly assistance during specimen processing, culturing and species identification. We also thank to all pathologists, data collectors and study participants in all study sites of northern Ethiopia.

\section{Competing Interests}

The authors have declared that no competing interest exists.

\section{References}

1. Iwenetu R, VandenHombergh J, Woldeamanuel Y, et al. Is Tuberculosis lymphadenitis over-diagnosed in Ethiopia? Comparative performance of diagnostic tests for mycobacterial lymphadenitis in a high burden country. Scandinavian J infect Dis. 2009; 41:462-468.

2. Sharma SK, Mohan A: Extra pulmonary tuberculosis. Indian J Med Res. 2004; 120:316-53.

3. Biadglegne F, Anagaw B, Anagaw B, Tesfaye W, Tessema B, Sack U, Rodloff AC. Tuberculosis Lymphadenitis in Northwest Ethiopia: Implications for Public Health. Open Journal of Medical Microbiology. 2013;3:18-24.

4. [Internet] World Health Organization. Global tuberculosis control; WHO report 2012. http://www.who.int/tb/data.

5. Ministry of Health of Ethiopia: First Ethiopia National Population based Tuberculosis survey Tuberculosis. Addis Ababa: MOH. 2011;

6. Ani AE. Advances in the laboratory diagnosis of M. tuberculosis. Ann Afr Med.2008; 7:57-61.

7. Ministry of Health of Ethiopia. Tuberculosis, Leprosy and TB/HIV Prevention and Control Programme Manual. Addis Ababa: MOH. 2008.

8. Sulaiman A, Afshan S, et al. A comparison of fine needle aspiration cytology with Ziehl Neelson staining technique in diagnosis of tuberculosis lymphadenitis. A comprehensive cytopathology. 2010;16:707-9.

9. Deutsces Institute für Normung. Medical microbiology-diagnosis of tuberculosis; Part 3: detection of mychobacteria by culture methods. DIN58943-3.DIN, Beuth Verlag, Berlin, Germany. 1986.

10. Beer J, Küchler R, Rodloff AC. Investigations about the possibility for testing the susceptibility of mycobacteria with the MB/BacT culture system. J Lab Med. 1997; 21:390-398.

11. Tessema B, Beer J, Emmrich F, Sack U, Rodloff AC. Analysis of gene mutations associated with isoniazid,rifampicin and ethambutol resistance among Mycobacterium tuberculosis isolates from Ethiopia. BMC Infectious Diseases. 2012; 12:37.
12. Hillemann D, Rüsch-Gerdes S, Richter E. Evaluation of the GenoType MTBDRplus assay for rifampin and isoniazid susceptibility testing of Mycobacterium tuberculosis strains and clinical specimens. J Clin Microbiol. 2007; 45:2635-40.

13. Huyen MN, Tiemersma EW, Lan NT, et al. Validation of the GenoType MTBDRplus assay for the diagnosis of multi drug resistant tuberculosis in South Vietnam. BMC Infectious Diseases. 2010; 10:149.

14. Causse M, Ruiz P, Gutierrez JB, Zerolo J, Casal M. Evaluation of new GenoType MTBDRplus for detection of resistance in cultures and direct specimens of M. tuberculosis. Int J Tuberc Lung Dis. 2008; 12:1456-1460.

15. Bezabih M, Mariam DW, Selassie SG. Fine needle aspiration of suspected tuberculous lymphadenitis. Cytopathology 2002; 13:284-290.

16. Zhang $Y$, Yew WW. Mechanisms of drug resistance in M. tuberculosis. Int J Tuberc Lung Dis. 2009; 13:1320-30.

17. Torres MJ, Criado A, Gónzalez N, et al. Rifampin and isoniazid resistance associated mutations in M. tuberculosis clinical isolates in Seville, Spain. Int J Tuberc Lung Dis. 2002; 6:160-3.

18. Hillemann D, Kubica T, Rüsch-Gerdes S, Niemann S. Disequilibrium in distribution of resistance mutations among Mycobacterium tuberculosis Beijing and non-Beijing strains isolated from patients in Germany. Antimicrob Agents Chemother. 2005; 49:1229-31.

19. Lee AS, Lim IH, Tang LL, Wong SY. High frequency of mutations in the rpoB gene in rifampin-resistant clinical isolates of $\mathrm{M}$. tuberculosis from Singapore. J Clin Microbiol. 2005; 43:2026-7.

20. Minh NN, Van Bac N, Son NT, et al. Molecular characteristics of rifampcin- and isoniazid-resistant Mycobacterium tuberculosis strains isolated in Vietnam. J Clin Microbiol. 2012;50:598-601

21. Bártfai Z, Somoskövi A, Ködmön C, et al. Molecular characterization of rifampin resistant isolates of $M$. tuberculosis from Hungary by DNA sequencing and the line probe assay. J Clin Microbiol. 2001; 39:3736-9.

22. Paluch-Oles J, Kozio1-Montewka M, Magrys A. Mutations in the rpoB gene of rifampin-resistant Mycobacterium tuberculosis isolates from Eastern Poland. New Microbiol. 2009; 32:147-52.

23. Sheng J, Li J, Sheng G, et al. Characterization of rpoB mutations associated with rifampin resistance in Mycobacterium tuberculosis from eastern China. J Appl Microbiol. 2008; 105:904-11.

24. Ballif M, Harino P, Ley S,et al. Drug resistance-conferring mutations in Mycobacterium tuberculosis from Madang, Papua New Guinea. BMC Microbiology 2012;12:191.

25. Bostanabad SZ, Titov LP, Bahrmand A, et al. Detection of mutation in Isonized resistant mycobacterium tuberculosis isolates from tuberculosis patients in Belarus. Ind J Med Microbiol. 2008; 26:143-7.

26. Zheltokjva EA, Chernousova LN, Smirnova TJ, et al. Molecular genetic typing Mycobacterium tuberculosis strains isolated from patents in the samapa region by the restriction DNA fragment length polymorphism ZH. Microbial (Moscow). 2004; 5:39-43.

27. Herrera-Leon, Molina L, Saiz T, et al. New multiplex PCR for rapid detection of isoniazid-resistant mycobacterium tuberculosis clinical isolates. Antimicrob Agents Chemother. 2005; 49:144-7.

28. Valvatne $H$, Syre $H$, Kross $M$, et al. Isoniazid and rifampicin resistance-associated mutations in Mycobacterium tuberculosis isolates from Yangon, Myanmar: implications for rapid molecular testing. Antimicrob Agents Chemother. 2009; 64:694-701.

29. Soudani A, Hadjfredj S, Zribi M, et al. Genotypic and phenotypic characteristics of Tunisian isoniazid resistant Mycobacterium tuberculosis strains. J Microbiol. 2011; 49:413-7.

30. Bolotin S, Alexander DC, Chedore P, Drews SJ, Jamieson F. Molecular characterization of drug-resistant Mycobacterium tuberculosis isolates from Ontario, Canada. J Antimicrob Chemother. 2009; 64:263-6. 